Bioscientia Medicina: Journal of Biomedicine \& Translational Research

Journal Homepage: www.bioscmed.com

\title{
The Potential of Bilimbi Leaves (Averrhoa bilimbi Linn.) Extract as Irrigation Solution to Remove Smear Layer in Dental Root Canal: An Invitro Study Windy Fanika Putri ${ }^{*}$, Steven Wijaya ${ }^{1}$, Dian Soraya Tanjung ${ }^{1}$ \\ ${ }^{1}$ Dentistry Education Program, Faculty of Dentistry, Universitas Prima Indonesia, Medan, Indonesia
}

\section{A R T I C L E I N F O}

\section{Keywords:}

Averrhoa bilimbi leaves extract

Smear layer

Pulpa

Dental root canal

Irrigation solution

\section{*Corresponding author: \\ Windy Fanika Putri \\ E-mail address: windyfanikaa16@gmail.com}

All authors have reviewed and approved the final version of the manuscript.

\section{https://doi.org/10.37275/bsm.v6i5.497}

\begin{abstract}
A B S T R A C T
Background. Root canal treatment is performed to eliminate the infection in the pulp tissue. One of the critical steps in root canal treatment is irrigation, which aims to clean debris and smear layer. This study aims to compare the effectiveness of star fruit extract (Averrhoa bilimbi Linn.) at concentrations of 5\%, $10 \%, 15 \%$, and $20 \%$ with EDTA $17 \%$ in cleaning the smear lay-er on the onethird of apical root canals. Methods: This type of research is an experimental in vitro laboratory with a post-test only con-trol group design. The sample of this study consisted of 25 premolars which were randomly divided into five groups. The teeth were instrumented with a K-file and irrigated with the fol-lowing materials: groups I, II, III, and IV using bilimbi leaves extract, each with concentrations of $5 \%, 10 \%, 15 \%$, and $20 \%$ and group V (positive control). ) using $17 \%$ EDTA. SEM (scan-ning electron microscope) was used to measure the cleanliness score of the smear layer on the apical third of the root canal. This study showed that bilimbi leaves extract was able to clean the smear layer on the one-third of the apical root canal. Results: The results of the Kruskal-Wallis statistical test showed a significant difference $(p<0.05)$ between all treatment groups. The highest average smear layer cleanliness score in the apical third of the root canals was EDTA 17\%, while the lowest average smear layer cleanliness score was 5\% bilimbi leaves extract. Conclusion: Bilimbi leaves extract with a concentration of $20 \%$ was considered more effec-tive among the extract groups, and $17 \%$ EDTA was the most effective in cleaning the smear layer on one-third of the root canals.
\end{abstract}

\section{Introduction}

Root canal treatment is carried out to eliminate the infection in the pulp tissue. ${ }^{1}$ Procedure steps carried out in root canal treatment are consist of access cavity preparation, cleaning, shaping, and root canal filling (obturation). ${ }^{2}$ Root canal preparation will produce organic pulp material and organic dentin debris that accumulates in the root canal wall of the tooth, resulting in an amorphous and irregular smear layer. The smear layer contains organic and inorganic layers, including fragments of the odontoblastic process, microorganisms, and necrotic tissue. Organic debris in the smear layer is a substrate for bacterial growth. It can inhibit attachment of sealer, allow leakage and reinfection to the root canal wall. ${ }^{3}$

Irrigation is one of the steps in root canal treatment that aims to remove debris and smear layer, helps remove bacteria, and as a lubricating agent to remove remnants of dentin tissue and pulp during instrumentation, including sodium hypochlorite (NaOCl), chlorhexidine ( $\mathrm{CHX}), \quad$ and ethylenediaminetetraacetic acid (EDTA). EDTA $17 \%$ is one of the irrigation materials that is often used in dental practice today because this material can bind $\mathrm{Ca}+$ ions from the dentin so that it will soften the 
dentin, simplifying the process of preparation and treatment of root canals of teeth that have undergone internal mineralization in the root canal system. $17 \%$ EDTA has chelation properties to clean the smear layer. ${ }^{4}$ However, root canal irrigation materials derived from chemical substances have a high level of toxicity and can damage cells and tissues when used, the effects of which vary from pain, irritation, oedema to bleeding in the root canal of teeth. ${ }^{5}$

Alternative materials are needed for root canal irrigation of teeth derived from medicinal plants. One of the medicinal plants used as an alternative material for root canal irrigation is bilimbi leaves. Bilimbi leaves have low toxicity, are easy to obtain, and are inexpensive. The bilimbi plant (Averrhoa bilimbi Linn.) belongs to the Oxalidaceae family, and this plant is commonly found in Indonesia. ${ }^{6}$ In addition to this plant being readily available, this plant also has properties as antidiabetic, antioxidant, antifungal, and antibacterial as for the content contained in the leaves of bilimbi in the form of flavonoids, triterpenoids, saponins, alkaloids, sulfur, formic acid, peroxidase, calcium oxalate, calcium citrate, tannins, and several minerals, especially calcium and potassium. ${ }^{6-7}$

Bilimbi leaves extract at a concentration of $15 \%$ was effectively used as a cleaning agent for dental root canal debris. ${ }^{6}$ Another study showed that $100 \%$ bilimbi juice (Averrhoa bilimbi Linn.) could clean the smear layer with a higher cleanliness value than polyacrylic acid. A scanning electron microscope (SEM) is a tool that can measure the level of cleanliness of the root canal walls by looking at the topography of the smear layer and debris on the root canal walls with high magnification resolution. ${ }^{8}$ This study was aimed to compare the effectivity of bilimbi leaves extract in concentrations of $5 \%, 10 \%, 15 \%$ and $20 \%$ with $17 \%$ EDTA as an alternative irrigation material to clean the smear layer on the tooth root canal walls.

\section{Methods}

This research is an in vitro experimental study. The bilimbi leaves were first washed and cleaned with running water, then dried in an oven at $600 \mathrm{C}$. Next, the chopping process was carried out to obtain the simplicia of bilimbi leaves. The simplicia of bilimbi leaves was extracted with $70 \%$ ethanol as solvent by the maceration method. There were five treatment groups in this study: the control group irrigated with EDTA $17 \%$ and the group irrigated with bilimbi leaves extract at various concentrations $(5 \%, 10 \%, 15 \%$, and $20 \%)$.

The object of study was the mandibular premolars. All samples were cleaned first with an electric scaling tool to be free from tartar, and then the samples were immersed in $0.9 \%$ saline solution. Before use, all samples were prepared for access cavity using round and tapered diamond bur, extirpation of the pulp tissue, measurement of working length, and root canal preparation using step-back technique using K-file size \#15-60. Every change of K-File, $3 \mathrm{ml}$ of $2.5 \% \mathrm{NaOCl}$ solution was irrigated. The root canals were rinsed with $3 \mathrm{ml}$ of $0.9 \%$ saline solution and dried using a paper point, then given a cotton swab and temporarily covered with cavitary material.

Dental samples were randomly divided into five groups, consisting of 5 dental samples. Dental samples in group I were irrigated with bilimbi leaves extract 5\% solution, group II was irrigated with a $10 \%$ bilimbi leaves extract solution, group III was irrigated with a $15 \%$ bilimbi leaves extract solution, group IV was irrigated with a $20 \%$ bilimbi leaves extract solution concentration, and group $\mathrm{V}$ was irrigated with $17 \%$ EDTA solution.

All samples from each group that had been prepared and irrigated root canals were incised using a diamond disc bur sagittally on the buccal, lingual, and horizontal sections, which were used as a guide for cutting. After that, the sample was cut horizontally at a distance of $4 \mathrm{~mm}$ from the tip of the apex and used a chisel to divide into two equal parts. The apical third of the tooth placed in the sample holder was then given a gold coating. After that, a photoshoot was carried out using an SEM tool with a magnification of 5000x. This study was observed by two observers who had made an agreement in determining the assessment and scoring for each sample that had taken SEM photos.

The assessment of the cleanliness score of the smear layer on the root canal wall consists of 4 scores, 
namely: score 1 (little or no smear layer, covering $<25 \%$ of dentinal tubules); score 2 (slightly to moderate, covering $25 \%$ - 50\% of dentinal tubules); a score of 3 (moderate, covering 50\% - 75\% of dentinal tubules), and a score of 4 (severe, covering more than $75 \%$ of dentinal tubules). Data analysis was carried out with the help of SPSS version 25 software. First, a univariate analysis was performed to present the data's frequency distribution, and bivariate analysis was performed using the Kruskal Walis and Mann Whitney test.

\section{Results}

Table 1 shows that the treatment group irrigated with EDTA $17 \%$ had the highest smear layer cleanliness score, namely a score of 1 as much as one sample and bilimbi leaves extract concentrations of $5 \%$, $10 \%$, and $15 \%$ had the lowest smear layer cleanliness score, namely a score of 4 , each were two, two, and one sample, respectively.

Table 1. Frequency of cleanliness score results of smear layer

\begin{tabular}{|c|c|c|c|c|c|}
\hline \multirow{3}{*}{ Score } & \multicolumn{4}{|c|}{ Frequency (n) } & \multirow{3}{*}{ EDTA $17 \%$} \\
\hline & \multicolumn{4}{|c|}{ Bilimbi leaves extract concentration } & \\
\hline & $\mathbf{5 \%}$ & $10 \%$ & $15 \%$ & $20 \%$ & \\
\hline $\mathbf{1}$ & - & - & - & - & 1 \\
\hline 2 & - & 1 & - & 1 & 3 \\
\hline 3 & 3 & 2 & 4 & 4 & 1 \\
\hline 4 & 2 & 2 & 1 & - & - \\
\hline Total & 5 & 5 & 5 & 5 & 5 \\
\hline
\end{tabular}

Before calculating the data, the results of the two observers were carried out by the Cohen's Kappa test, which aims to see if the results of the two observers have a significant difference or not. It can be stated that there is no significant difference in the results of the smear layer hygiene assessment score on one-third of the root canals between observer one and observer 2 with $\mathrm{p}>0.05$, so the score data is declared valid. Then, the research data was continued with the Shapiro-Wilk normality test. The results obtained that the data were not normally distributed, so the research data analysis used was the Kruskal Wallis and Mann Whitney test.

Based on the Kruskal Wallis test results, p-value $=$ $0.034(p<0.05)$, which means that there is a significant difference in the smear layer cleanliness score in onethird of the root canals between all treatment groups. The mean \pm standard deviation (SD) of smear layer hygiene scores in one third of the root canals after irrigation with bilimbi leaves extract 5\%, 10\%, 15\%,
$20 \%$, and 17\% EDTA respectively were as follows, namely $3,40 \pm 0.548 ; 3.20 \pm 0.837 ; 3.20 \pm 0.447 ; 2.80$ \pm 0.447 ; and $2.00 \pm 0.707$. These results show that the lowest average smear layer cleanliness score was in one-third of the root canals, namely $5 \%$ bilimbi leaves extract, and the highest average smear layer cleanliness score was in one-third of the root canals, namely EDTA $17 \%$.

The research data analysis was continued with the Mann Whitney statistical test, which was used to determine the differences between the two research groups. Based on the results of the Mann Whitney test, it showed that there was a significant difference in the smear layer cleanliness score in one-third of the root canals between the $5 \%$ bilimbi leaves extract group and $17 \%$ EDTA $(p=0.016)$ and the $10 \%$ bilimbi leaves extract group with $17 \%$ EDTA $(p=0.049)$. At the same time, there was no significant difference between the other groups $(\mathrm{p}>0.05)$. 

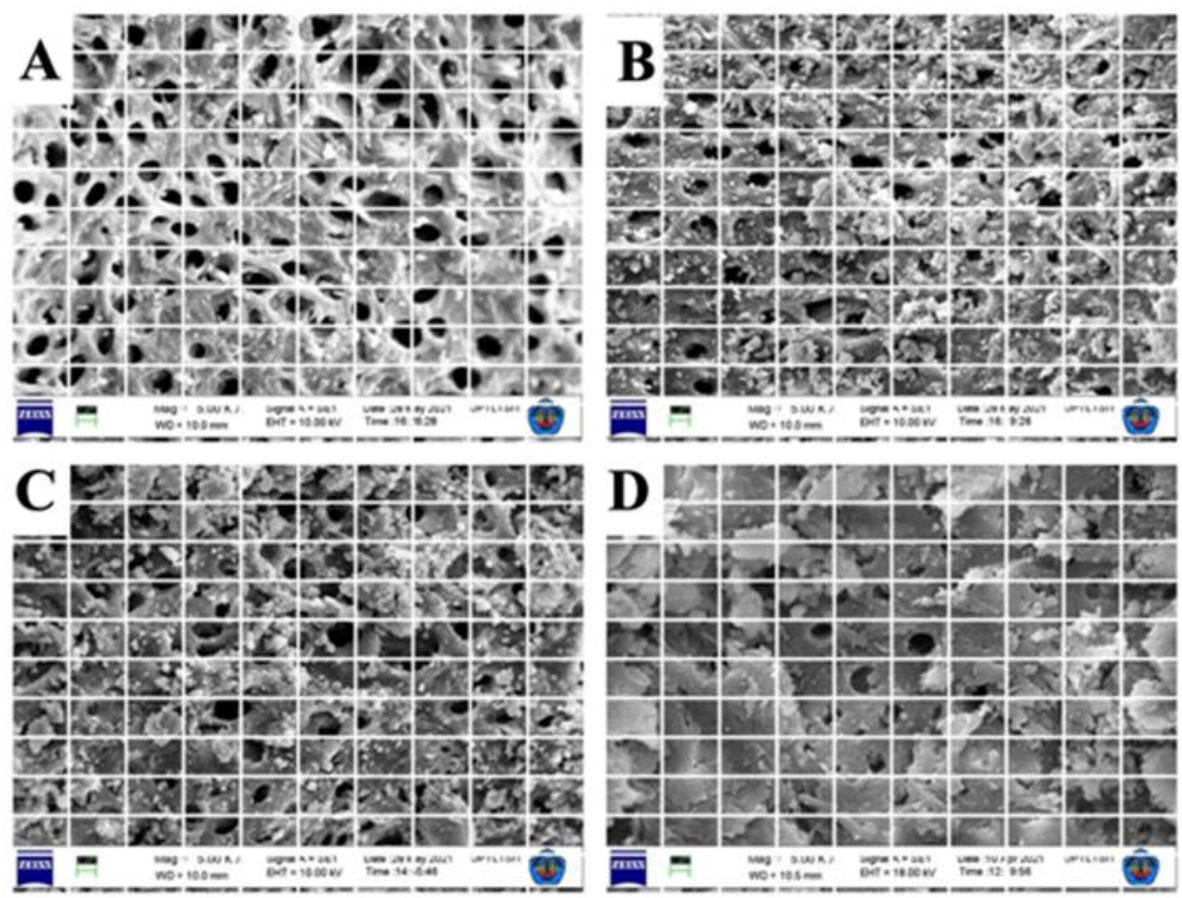

Figure 1. SEM photomicrograph image with 5000x magnification on the surface of the dentin wall in the apical third of the root canal irrigated with; A. EDTA 17\% (Score 1); B. Bilimbi leaves extract 15\% concentration (Score 2); C. Bilimbi leaves extract 5\% concentration (Score 3); D. Bilimbi leaves extract 5\% concentration (Score 4).

\section{Discussion}

This study used irrigation agent EDTA $17 \%$ as a positive control group and natural irrigation from bilimbi leaf extract (Averrhoa bilimbi Linn.) with four different concentrations, namely $5 \%, 10 \%, 15 \%$, and $20 \%$, as the treatment group. The concentration used in this study is in line with previous studies, which stated that if the concentration was used above $20 \%$, it would be toxic to the tissues around the apical area of the tooth, where one of the requirements for an irrigating solution was non-toxic. ${ }^{8}$ Kruskal Wallis statistic obtained that $\mathrm{p}$-value $=0.034(\mathrm{p}<0.05)$ which means that there is a significant difference in the smear layer cleanliness score in one third of the root canals between all groups and the mean \pm standard deviation (SD) of the smear layer cleanliness score at one-third of the root canals after being irrigated with bilimbi leaf extract $5 \%, 10 \%, 15 \%, 20 \%$ and $17 \%$ EDTA, respectively $3.40 \pm 0.548 ; 3.20 \pm 0.837 ; 3.20 \pm 0.447$; $2.80 \pm 0.447 ; 2.00 \pm 0.707$.

From these results, it can be concluded that $17 \%$ EDTA had the highest average smear layer cleanliness score in the apical third of the root canals, while 5\% bilimbi leaves extract had the lowest smear layer cleanliness score in the apical third of the root canals. However, among extracts of bilimbi leaves, a concentration of $20 \%$ had the highest mean smear layer cleanliness score in the apical third of the root canals. It can be concluded that the higher the concentration of bilimbi leaves extract, the higher the smear layer cleanliness score in the apical third of the root canal. ${ }^{9}$ In the Mann-Whitney test results, the ratio between the EDTA-irrigated group was $17 \%$ and the irrigated with $20 \%$ bilimbi leaves extract showed no significant difference.

From these results, it can be interpreted that the $20 \%$ bilimbi leaves extract can be an irrigation liquid almost equal to $17 \%$ EDTA. However, the average dental root canal smear cleanliness score after being irrigated with $17 \%$ EDTA is smaller than $20 \%$ star fruit leaf extract. ${ }^{10}$ The ability of $17 \%$ EDTA as an irrigation liquid and superior to bilimbi leaves extract was probably due to its ability to remove inorganic substances from intracanal debris. The ability of $17 \%$ 
EDTA to remove the smear layer was more effective than sodium hypochlorite. However, 17\% EDTA used as a single irrigation solution was not effective at removing the entire stain layer. ${ }^{11-12}$

\section{Conclusion}

The 20\% concentration of bilimbi leaves extract was considered more effective than other extract concentrations and almost equaled the 17\% EDTA based on the average smear layer cleanliness score.

\section{References}

1. Yodasari L, Ratih DN. One visit root canal treatment using rotary instrument followed direct technique composite restoration. Majalah Kedokteran Gigi. 2017; 3(2).

2. Wedagama DM, Hartini AAA, Ernawati L. Single visit endodontic treatment on left maxillary first molar with reciprocal system. IJKG. 2019; 15(1).

3. Alamoudi RA. The smear layer in endodontic: to keep or remove- an update overview. Saudi Endod J. 2019; 9(2): 71-81.

4. Tamara NA, Zubaidah N, Mudjiono M. The effectiveness of $2.5 \% \mathrm{NaOCl}$ irrigation and $17 \%$ EDTA against the sealing ability of resin paste. Conservative Dentistry. 2019; 9(2).

5. Hillesheim LC, Hoffmann JB, Schuldt DPV, Bortoluzzi EA, Teixeira CS. Intracanal irrigating solutions prior to calcium hydroxide medication and its effects on root dentin strength. Braz Dental J. 2017; 28(1): 46-50.

6. Dumanauw JM, Fione VR. The effectiveness of bilimbi extract as dental antibacterial mouthwash. Proceeding Manado Health Polytechnic. 2017; 1(1).

7. Haapasalo $M$, Shen $Y$, Wang $Z$, Gao Y. Irrigation in endodontics. Br Dent J. 2014; 216(6): 299-303.

8. Hancerliogullari D, Erdemir A, Kisa U. The effect of different irrigation solutions and activation techniques on the expression of growth factors from dentine of extracted premolar teeth. Int Endod J. 2021; 54(10): $1915-24$

9. Alhassan AM, Ahmed QU. Averrhoa bilimbi Linn: A review of its ethnomedicinal uses, phytochemistry and pharmacology. J Pharm Bioallied Sci. 2016; 8(4): 265-71.

10. Matos FS, da Silva FR, Paranhos LR, Moura CCG, Valera MC. The effect of $17 \%$ EDTA and QMiX ultrasonic activation on smear layer removal and sealer penetration: ex vivo study. Sci Rep. 2020; 10: 10311.

11. Mohammadi $Z$, Shalavi S, Jafarzadeh $H$. Ethylenediaminetetraacetic acid in endodontics. Eur J Dent. 2013; 7 (Suppl 1): S135-42.

12. Prasad PS, Sam JE, Kumar A, Kannan K. The effect of $5 \%$ sodium hypochlorite, 17\% EDTA and triphala on two different rotary $\mathrm{Ni}-\mathrm{Ti}$ instruments: an AFM and EDS analysis. J Conserv Dent. 2014; 17(5): 462-6. 